\title{
VARIASI KOMPOSISI BAHAN GENTENG SOKA UNTUK MENDAPATKAN DAYA SERAP AIR YANG OPTIMAL
}

\author{
Musabbikhah ${ }^{1)}$; Sartono Putro') \\ 1) Jurusan Teknik Mesin AT.Warga \\ Email:mus_a2002@yahoo.com \\ Jl.Raya Solo Baki Km 2, Kwarasan, Solo Baru \\ 2) Jurusan Teknik Mesin Universitas Muhammadiyah Surakarta \\ Jl. A. Yani Kotak Pos 1 Pabelan Surakarta \\ Email: sartono_putro@ums.ac.id
}

\begin{abstract}
ABSTRAK
Genteng merupakan salah satu komponen penting pembangunan perumahan yang memiliki fungsi untuk melindungi rumah dari suhu,hujan maupun fungsi lainnya. Agar kualitas genteng optimal, maka daya serap air harus seminimal munhkin, agar kebocoran dapat diminimalisir. Metode yang digunakan untuk mengoptimalkan daya serap air genteng adalah Taguchi.

Dalam penelitian ini terdiri 4 variabel bebas masing-masing 2 level faktor yaitu tanahliat, (80\% dan 85\%), Pasir (14\% dan 10\%), semen merah (5\% dan 3.5\%), Dolumite (1\% dan 1.5\%)). Sedangkan variabel responnya adalah daya serap air. Karakteristik kualitas yang digunakan adalah smaller the better. Berdasarkan Analysis of Variansi menunjukkan bahwa untuk mengoptimalkan daya serap air, agra genteng tidak mudah bocor komposisi tanah liat, pasir, semen merah dan dolumite memberikan persen kontribusi masing-masing 16.45\%, 19.69\%, 20.59\% dan 5.27\%. Kondisi optimal daya serap air dicapai pada variasi A1B1C1D2, artinya komposisi tanah liat $80 \%$, pasir 14\%, semen merah 5\% dan dolumite $1.5 \%$. Perbandingan variasi kondisi sebelum dan sesudah dilakukan penelitian menunjukkan bahwa terjadi peningkatan nilai S/N dari (-20.454 menjadi -18.712), penurunan stadart deviasi drai (1.553 menjadi 1.25). Nilai Cp dan CPk mengalami peningkatan dari (0.999 menjadi 1.234), artinya bahwa proses pembuatan genteng Soka, capable karena nilai $C p>1$ seiring dengan meningkatnya fungsi nilai keuntungan sebesar 34.4 cents/\$1loss.
\end{abstract}

Kata kunci: Kekuatan Tekan, Metode Taguchi, Genteng Soka

\section{PENDAHULUAN}

Tingginya jumlah penduduk di Kabupaten Sukoharjo mendorong pembangunan fisik semakin meningkat, khususnya kebutuhan sektor perumahan. Untuk menjaga kelancaran pembangunan perumahan, maka bahan-bahan bangunan harus tersedia dalam kapasitas yang memadai. Genteng merupakan salah satu bahan dasar yang harus dipenuhi. Semakin tingginya pembangunan perumahan, maka kebutuhan akan bahan bangunan semakin meningkat. Peningkatan ini mencapai puncaknya, setelah terjadinya musibah gempa Jogyakarta dan sekitarnya pada tahun 2005. Musibah selanjutnya yaitu banjir dan 
tanah longsor pada tahun 2007 yang mengakibatkan sebagian wilayah Sukoharjo merupakan salah satu daerah yang terkena bencana alam tersebut.

Berdasarkan Survei Krenova tahun 2007, Kabupaten Sukoharjo yang terdiri dari 12 Kecamatan yang terbagi menjadi 17 Kelurahan, 150 Desa, 1.278 RW, dan 3.676 RT memiliki beberapa industri yang berpotensi dalam menunjang pembangunan dan Pendapatan Anggaran Daerah (PAD). Salah satu industri tersebut adalah industri genteng. Sentra industri genteng di Kabupaten Sukoharjo berada di Kecamatan Weru dan Mojolaban sebanyak 839 unit pengrajin dan menyerap 2.300 orang tenaga kerja. Jumlah produksinya mencapai 125.000 .000 buah per tahunnya.

Banyaknya sentra industri Genteng Soka dapat meningkatkan taraf hidup dan perekonomian masyarakat Kabupaten Sukoharjo karena dapat menyerap tenaga kerja sekitar.

Off line quality control merupakan pendekatan yang efektif untuk memperoleh produk/proses yang berkualitas tinggi dengan cepat, tepat dan biaya yang relatif murah. Aktivitas ini terdapat pada perencanaan produk, dan tahapan desain serta perencanaan produksi. Metode Taguchi menggabungkan teknik desain eksperimen dan quality loss. serta secara khusus diterapkan pada pengendalian kualitas "off line" yang dibedakan menjadi tiga tahap yaitu system design, parameter design dan tolerance design.

\section{TINJAUAN PUSTAKA}

\section{A. Proses Pembuatan Genteng}

Menurut (Musabbikhah, 2001), dalam pembuatan genteng Soka, langkah-langkah yang dilakukan adalah sebagai berikut :

1. Pencampuran komposisi bahan yang meliputi tanah liat, pasir, semen merah, dolumite dan air sesuai standart industri.

2. Selanjutnya campurkan bahan tambah hingga merata, hindarkan terjadi penumpukan antara bahan baku dengan bahan tambah yang dapat menyebabkan non homogenitas bahan.
3. Pencetakan, tujuannya agar terjadi pelapukan kembali, sehingga homogenitas dan suatu ikatan yang kuat antar butir-butir dari semua bahan baku dan bahan tambah yang lebih padat denagn kandungan udara lebih kecil(tidak terjadi ruang udara di dalamnya), karena akan mempengaruhi terjadinya daya serap air yang tinggi.

4. Pengeringan, dilakukan pada tempat yang terhindar dariudara lembab agargenteng menjadi benar-benar kering atau kadar air kecil sehingga kalau ditimbang tidak terlalu berat.

5. Pembakaran, dilakukan mengunakan kayu atau kulit padi.

6. Pembongkaran, dilakukan secara hati-hati untuk menghindrai retak atau pecah.

\section{B. Pengujian Daya Serap Air}

Agar dihasilkan mutu genteng yang baik, maka perlu memilih bahan-bahan yang baik, dan juga memperhatikan komposisi material yang digunakan serta homogenitas bahan. Kepadatan genteng dapat menghasilkan kekuatan genteng dan daya serap air yang kecil, sehingga kualitas genteng semakin baik. Besarnya daya serap air dirumuskan:

$\%$ daya serap air $=\frac{\text { Berat genteng kering }}{\text { Berat genteng basah }} \times 100 \%$

\section{Filosofi Taguchi}

Pengendalian kualitas dapat dibagi ke dalam dua tahap yaitu :

a). Pengendalian kualitas "off line" terkait dengan aktivitas selama pengembangan produk dan disain proses.

Aktivitas yang dilakukan adalah :

1). Mengidentikasikan kebutuhan konsumen dan yang diharapkan oleh konsumen.

2). Mendisain produk yang sesuai dengan harapan konsumen.

3). Mendisain produk secara konsisten dan secara ekonomi menguntungkan.

4). Mengembangkan secara jelas dan spesifik dari standar, prosedur dan peralatan. 
b). Pengendalian kualitas "On-line” terkait dengan proses selama produksi.

Pengendalian kualitas "On-line” berarti memelihara kekonsistenan produk dan proses sehingga meminimumkan variasi antar unit.

Taguchi mengusulkan langkah-langkah yang sistematis dalam melakukan eksperimen yaitu sebagai berikut: menyatakan permasalahan yang akan dipecahkan; penentuan tujuan penelitian; menentukan metode pengukuran; identifikasi faktor.

c) Brainstorming

d) Diagram Sebab Akibat (Ishikawa Diagram)

e) Memisahkan faktor kontrol dan noise faktor

f) Mengidentifikasi faktor yang mungkin berinteraksi.

g) Menggambarkan linear graph yang diperlukan untuk faktor kontrol dan interaksi.

h) Memilih Orthogonal Array

i) Memasukkan faktor dan atau interaksi ke dalam kolom

j) Melakukan percobaan

k) Analisis hasil eksperimen

l) Pemilihan level faktor untuk kondisi optimal.

m) Perkiraan rata-rata proses pada kondisi optimal

\section{Penerapan Metode Taguchi}

Metode Taguchi diperkenalkan oleh Genechi Taguchi pada tahun 1940 yang bertujuan untuk mengoptimalkan proses eksperimen. Metode taguchi berkembang berdasarkan pendekatan yang secara keseluruhan berbeda dengan metode konvensional dalam rekayasa kualitas. Dalam pengendalian kualitas Taguchi telah menggabungkan falsafahfalsafah besar yang ada pada industri manufaktur. Pendekatan metode Taguchi pada rancangan eksperimen diharapkan mampu menghasilkan pengembangan kualitas yang kokoh (robust) terhadap faktor noise.

Langkah-langkah yang dilakukan pada metode Taguchi adalah :

1). Identifikasi faktor, memisahkan faktor noise dan faktor kontrol
2). Penentuan level faktor sehingga diperoleh derajat bebas

3). Mengidentifikasi faktor yang mungkin berinteraksi

4). Memilih Orthogonal Array yang sesuai

5). Memasukkan faktor utama dan interaksi ke dalam kolom dengan bantuan linear graph atau triangular table.

6). Melakukan eksperimen

7). Menghitung Signal To Noise Ratio (S/N Ratio )

$\mathrm{S} / \mathrm{N}=-10 \log \mathrm{MSD}$

$\mathrm{S} / \mathrm{N}=-10 \log \left(\mathrm{y}_{1}{ }^{2}+\mathrm{y}_{2}{ }^{2}+\ldots+\mathrm{y}_{\mathrm{N}}{ }^{2}\right) / \mathrm{N} \ldots$

10).Menentukan kombinasi level faktor optimal untuk respon berdasarkan grafik dan tabel respon serta menentukan Confidence interval untuk S/N Ratio.

11).Percobaan konfirmasi

Hasil eksperimen konfirmasi akan menentukan apakah level faktor optimal yang diperoleh bisa diperluas ke skala industri.

Fungsi kerugian(Ross, 1996), dapat dibedakan menjadi tiga jenis yaitu:

1) Smaller the better

$\mathrm{L}(\mathrm{y})=\mathrm{k}(\mathrm{y}-\mathrm{m})^{2}$.

2) Nominal the better

$\mathrm{L}(\mathrm{y})=\mathrm{k}(\mathrm{y})^{2}$

3) Larger the better

$\mathrm{L}(\mathrm{y})=\mathrm{k}(1 / \mathrm{y})^{2}$

\section{METODE PENELITIAN}

Bahan yang dipergunakan untuk penelitian ini adalah tanah liat, pasir, semen merah, air, dolumite, kaoline, barium Carbonat.

Peralatan yang dipergunakan antara lain molen, alat cetak,tungku pembakaran, skop, ayakan pasir, gerobak, timbangan,

1. Variabel Bebas (dependent variable): komposisi bahan genteng yang meliputi tanah liat, pasir, semen merah, dan dolumite.

2. Variabel Terikat'(independent variable): Daya serap air genteng.

3. Karakteristik kualitas yang digunakan: Smaller the better 
4. Pemilihan array orthogonal : L8 (27) Alasan penggunaan array orthogonal ini, jumlah total derajat bebas adalah 7 , dengan 2 level faktor, sehingga matrik yang paling mendekati adalah L8 $\left(2^{7}\right)$.

Tabel 1. OA L8 (27)

\begin{tabular}{|l|c|c|c|c|c|c|c|}
\hline \multirow{2}{*}{ Eksp } & \multicolumn{7}{|c|}{ Columns } \\
\cline { 2 - 8 } & 1 & 2 & 3 & 4 & 5 & 6 & 7 \\
\hline Trial\#1 & 1 & 1 & 1 & 1 & 1 & 1 & 1 \\
\hline Trial\#2 & 1 & 1 & 1 & 2 & 2 & 2 & 2 \\
\hline Trial\#3 & 1 & 2 & 2 & 1 & 1 & 2 & 2 \\
\hline Trial\#4 & 1 & 2 & 2 & 2 & 2 & 1 & 1 \\
\hline Trial\#5 & 2 & 1 & 2 & 1 & 2 & 1 & 2 \\
\hline Trial\#6 & 2 & 1 & 2 & 2 & 1 & 2 & 1 \\
\hline Trial\#7 & 2 & 2 & 1 & 1 & 2 & 2 & 1 \\
\hline Trial\#8 & 2 & 2 & 1 & 2 & 1 & 1 & 2 \\
\hline
\end{tabular}

5. Data daya serap air dengan 2 kali replikasi.

6. Metode yang digunakan: Taguchi

\section{HASIL DAN PEMBAHASAN}

Hasil perhitungan signal to noise ratio dengan metode Taguchi pada daya serap air genteng „Soka” ditunjukkan pada tabel 2.

\section{Tabel 2. S/N Ratio of Experimental} Trial Result

\begin{tabular}{|l|l|l|l|}
\hline & Sampel\#1 & Sampel\#2 & S/N Ratio \\
\hline Trial\#1 & $8.33 \%$ & $10.53 \%$ & -19.549 \\
\hline Trial\#2 & $11.11 \%$ & $8.33 \%$ & -19.842 \\
\hline Trial\#3 & $10.81 \%$ & $8.33 \%$ & -19.691 \\
\hline Trial\#4 & $13.51 \%$ & $10.53 \%$ & -21.665 \\
\hline Trial\#5 & $11.11 \%$ & $10.53 \%$ & -20.688 \\
\hline Trial\#6 & $10.53 \%$ & $10.81 \%$ & -20.565 \\
\hline Trial\#7 & $10.53 \%$ & $11.11 \%$ & -12.688 \\
\hline Trial\#8 & $8.33 \%$ & $13.51 \%$ & -21.003 \\
\hline
\end{tabular}

Kondisi optimum dicapai pada level faktor A1B1C1D2 yaitu komposisi tanah liat 80\%, pasir 14\%, semen merah 5\% dan dolumite 1.5\% seperti ditunjukkan pada tabel 3.

Tabel 3. Optimum Condition and Performance

\begin{tabular}{|c|l|l|c|c|}
\hline & \multicolumn{1}{|c|}{ Factors } & Level Desc & Level & Contrib \\
\hline 1 & A:Tanah liat & $80 \%$ & 1 & 0.274 \\
\hline 2 & B:Pasir & $14 \%$ & 1 & 0.300 \\
\hline 3 & INTERACT 1x2 & *INTER* & 1 & 0.190 \\
\hline 4 & C:Semen merah & $5 \%$ & 1 & 0.307 \\
\hline 5 & INTERACT $1 \times 4$ & $*$ INTER* & 1 & 0.259 \\
\hline 6 & INTERACT $2 x 4$ & $*$ INTER* & 2 & 0.264 \\
\hline 7 & D:Domulite & $1.5 \%$ & 3 & 0.155 \\
\hline
\end{tabular}

Berdasarkan hasil perhitungan S/N Ration daya serap air genetng press, maka dapat diketahui faktor-faktor yang dapat memberikan respon terendah sampai yang tertinggi terhadap tinggi rendahnya daya serap air genteng yang ditampilkan dalam bentukl tabel faktor utama dan faktor interaksi. Tabel respon daya serap air genteng ditunjukkan pada tabel 4.

Tabel 4. Respon Faktor Utama(\%)

\begin{tabular}{|c|c|c|c|c|c|c|c|}
\hline Level & A & B & AXB & C & AXC & BXC & D \\
\hline 1 & 10.4 & 10.4 & 10.5 & 10.4 & 10.4 & 11 & 11 \\
\hline 2 & 10.8 & 10.8 & 10.8 & 10.8 & 10.8 & 10.2 & 10.3 \\
\hline
\end{tabular}

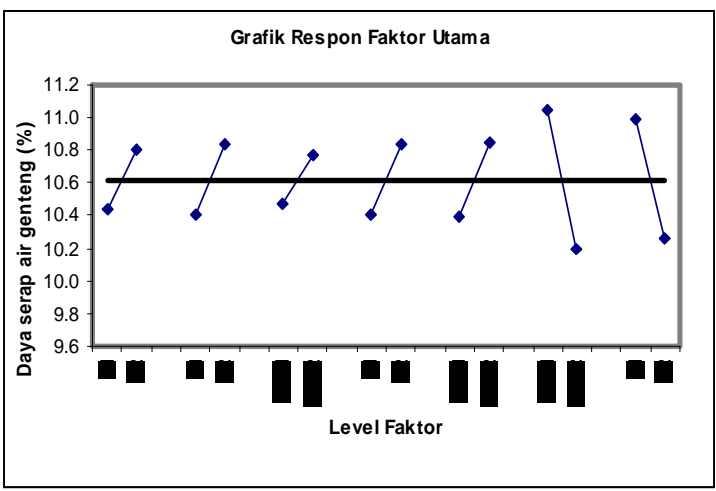

Gambar 1. Respon Faktor Utama 
Dalam penelitian daya serap air genteng, terdapat 3 interaksi antar kedua level faktor seperti ditunjukkan pada tabel 5.

Tabel 5. Respon Faktor Interaksi
Atau MSD $=10 \wedge[-(\mathrm{S} / \mathrm{N}) / 10]=74.34$

Dimana : $\mathrm{MSD}=\left[\right.$ Avg. $\left.(\mathrm{yi})^{\wedge} 2\right]=\operatorname{Yexp}^{\wedge} 2$

$\operatorname{Exp}=\mathrm{SQR}(\mathrm{MSD})$

Expectedperformancein QC units is :

Y exp = 8.63 Qcunit

Kondisi optimum; $\mathrm{S} / \mathrm{N}=-18.712$

Besarnya main efect dalam penelitian daya serap air genteng ditunjukkan pada tabel 6 .

Tabel 6. Main Effect Daya Serap Air

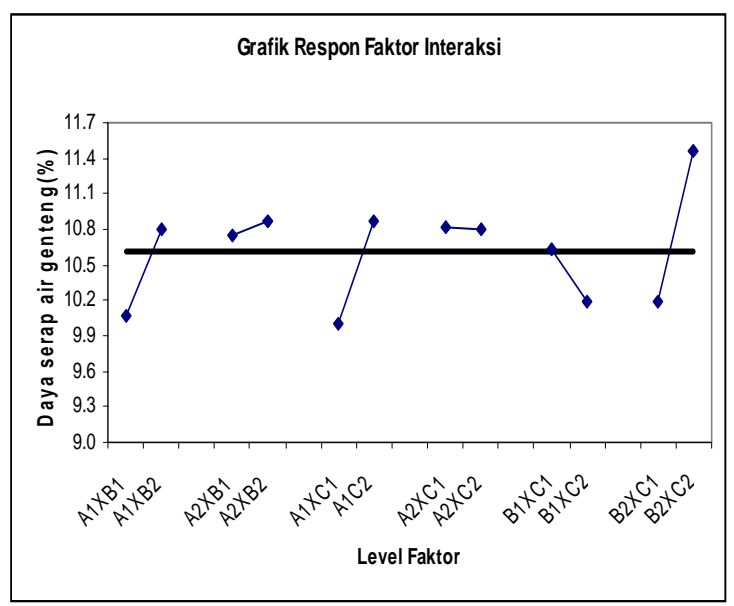

\begin{tabular}{|c|c|c|c|c|c|c|c|c|}
\hline Level & A1Fachers & \multicolumn{7}{|c|}{ 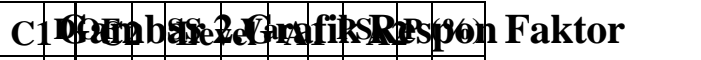 } \\
\hline B1 & $\begin{array}{l}\text { A:Tanah liat } \\
101 \\
\end{array}$ & & & 0.60 & 0.601 & earadk & Si申 & \\
\hline $\begin{array}{l}191 \\
2 \\
\end{array}$ & B:Pasir & & 1 & 0.72 & 0.72 & 0.72 & 19.69 & \\
\hline$\overline{B Z}$ & INOFERACP & 70. & 214 & 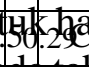 & 20.69 & 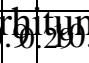 & 895 & litun- \\
\hline 4 & C:Semen met & 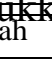 & & 0.75 & 0.75 & \begin{tabular}{|l|l|} 
& 1 \\
& 0.75 \\
\end{tabular} & 20.59 & \\
\hline 5 & INTERACT 1 & $1 \times 4$ & bel 6 & A.5. & 0.54 & $6 \mathbf{f a}$ & rianc & JOVA) \\
\hline 6 & INTERACT 2 & & 1 & 0.56 & 0.56 & 0.56 & 15.32 & \\
\hline 7 & D:Domulite & & 1 & 0.19 & 0.19 & 0.19 & 5.27 & \\
\hline Tot & & & 7 & 3.67 & & & $100 \%$ & \\
\hline
\end{tabular}

Estimate of expected result from $\mathrm{S} / \mathrm{N}$ ration adalah:

$\mathrm{S} / \mathrm{N}=-10 \log (\mathrm{MSD})=-18.712$

\begin{tabular}{|l|l|c|c|c|}
\hline & \multicolumn{1}{|c|}{ Factors } & Level 1 & Level 2 & L2-L1 \\
\hline 1 & A:Tanah liat & -20.187 & -20.376 & -0.549 \\
\hline 2 & B:Pasir & -20.161 & -20.762 & -0.601 \\
\hline 3 & INTERACT 1x2 & -20.27 & -20.652 & -0.383 \\
\hline 4 & C:Semen merah & -20.154 & -20.768 & -0.615 \\
\hline 5 & INTERACT $1 \times 4$ & -20.202 & -20.721 & -0.519 \\
\hline 6 & INTERACT 2x4 & -20.726 & -20.196 & 0.529 \\
\hline 7 & D:Domulite & -20.617 & -20.306 & 0.31 \\
\hline
\end{tabular}

Berdasarkan hasil perhitungan $\mathrm{S} / \mathrm{N}$ ratio yang dilakukan, menunjukkan bahwa hasil optimal yang dicapai untuk daya serap air genteng masih berada dalam batas spesifikasi yang ditentukan $90 \%$, sehingga penelitian ini dapat diperluas ke skala yang industri.

\section{Pembahasan}

Genteng Soka merupakan salah satu komponen yang sangat penting dalam sektor pembangunan perumahan. Oleh sebab itu genteng yang digunakan harus berkualitas agar dapat meraih pangsa pasar. Berdasarkan ANOVA diketahui bahwa faktor-faktor yang mempengaruhi kualitas genteng adalah komposisi tanah liat, pasir, semen merah dan dolumite serta interaksi antar dua faktor. Software yang digunakan untuk membantu mengoptimalkan kadar air Genteng Soka adalah Desain Taguchi. Besarnya S/N optimal pada Genteng Soka dicapai pada level faktor A1B1C1D2 yaitu artinya komposisi tanah liat $80 \%$, pasir $14 \%$, semen merah $5 \%$ dan dolumite $1.5 \%$. 
Dalam penelitian ini, pengurangan variasi ditunjukkan adanya perbaikan kondisi yang mendekati nilai target dan variasinya menurun. Hal ini terbukti bahwa nilai CP dan CPk meningkat dari 0.999 menjadi 1.234 . Ini menunjukkan bahwa proses pembuatan genteng Soka sangat capable ditinjau dari daya serapm air, karena nilai $\mathrm{CPk}>1$. Perbaikan ini juga diperoleh dari penurunan standar deviasi dari 1.553 pada kon-disi awal, menjadi 1.25 pada kondisi akhir. Nilai S/N Ratiomengalami peningkatan dari (-20.545) pada kondisi awal menjadi (-18.712) pada kondisi akhir. Adapun besarnya loss fuction yang diperoleh dalam proses pembuatan genteng Soka ini sebesar 34.4 cent/\$ 1loss. Hal ini menunjukkan bahwa metode Taguchi mampu mengoptimalkan daya serap air genteng Soka sehingga kualitas genteng meningkat karena semakin kecil daya sreap air, kemungkinan terjadi kebocoran genteng semakin kecil.

\section{SIMPULAN}

Berdasarkan hasil pengamatan dan pembahasan penelitian ini dapat disimpulkan sebagai berikut.

1. Faktor-faktor yang mempengaruhi gas daya serap air genteng soka adalah adalah komposisi tanah liat, pasir, semen merah, dolumite dan interaksi antara kedua faktor tersebut.

2. Besarnya taksiran optimal yang dapat mengoptimalkan daya serap air genteng adalah -18.712.

3. Besarnya $\mathrm{S} / \mathrm{N}$ yang dapat mengoptimalkan respon daya serap air genteng dicapai pada level faktor A1B1C1D2 artinya komposisi tanah liat $80 \%$, pasir 14\%, semen merah 5\% dan dolumite $1.5 \%$.

\section{DAFTAR PUSTAKA}

Basuki; Musabbikhah, 2003, Penerapan Prosedur Multi Respon Signal To Noise Pada gas buang NOx dan CO, Jurnal Ilmiah Teknik Industri, Universitas Muhammadiyah Surakarta, Vol 02 Nomor 1, 1-8.

Douglas C. Montgomery, 1997, Design and Analysis Experimen, Fourth Edition, Arizona state University.

Lochner Rhand Matar, 1999, Designing For Quality, An Introduction to Teh Best of Taguchi and Western Method of Statistical Experimental Design Quality Resources and ASQC Quality, Press Milwaukee, Wisconsin, New York.

Musabbikhah, Evy H, 2003, Rancangan Furan dengan Prosedur MRSN, Prosiding Seminar Nasional, ITS, Surabaya.

Musabbikhah, 2004, Minimasi Kadar Polutan HC dan CO2 dengan Prosedur MRSN Pada Metode Taguchi, Proceedings Seminar Nasional Universitas Setia Budi Surakarta, 48-57.

Nicolo Belavendram., 1999, Quality By Design, Second Edition, Prentice Hall, International.

Phillip J. Ross, 1998, Taguchi Techniques for Quality Engineering, Second Edition, MC Graw Hill, Singapore.

Tong, L and Chao,T Su., 1997, Optimizing Multirespon Problems In The Taguchi Methods by Fuzzy Multiple Attribute Decision Making, Quality And Reability Engineering International, Vol 13, 25-34.

www.gentengpelita.com 